\title{
Enhancing Public Speaking Skills among B.Tech Students Using JAM Sessions:a practical Research
}

\author{
Gomatam Mohana Charyulu, Vijaya Babu Palukuri, G Nageswara Rao, U Sriranganath
}

\begin{abstract}
There is a dire need of enhancing public speaking skills among all the students in general and B.Tech students in particular consent to the study and advances of multidimensional learning tools. It creates a kind opportunity for the learners to practice and improve their PSS. The present study examines a potential learning situation of the select students of B.Tech by using the application of Just A Minute (JAM) session as a tool in the development of their PSS. It needs from the speaker a coherent use of their verbal and non verbal expressions. Timely depth with adequate exactness is always a challenging. However, for the last a few decades, PSS have been undertaken to support individual performance at various placements. First the application and studies exhibit the capable observed results in the various sessions organised in a systematic manner. This paper titled: "Enhancing Public Speaking Skills among B.Tech Students Using JAM Sessions: A practical Study" explores the use of JAM in learning application with real public task in the session. The results of this study facilitate to understand the challenges and implication of testing the system in a Practical Setting. It also shows the authentic collision compared to the use of such practical sessions in enhancing PSS.
\end{abstract}

Keywords: challenges, coherent, implications, JAM, PSS .

\section{INTRODUCTION}

Expressing ideas in an impressive and creative manner is an excellent art. One can inspire through the speech by using novel ideas to encourage and provoke the listeners towards their objectives and goals. Therefore Public speaking is the major quality of the presenter to share, exchange, express and propose various views. The study of public speaking is not a new thing to human. It has a long history of years. At present, to speak or present the ideas successfully is the major consideration to the educated professionals. It is also looked as a core competence. Such an important and accurate study on how to converse efficiently is resistant thought of the contemporary age. Various researches are going at various places on how to enhance public speaking skills among the public. Extensive study with various tools on this Public Speaking skills are taken up and training, response aspects

Revised Version Manuscript Received on 10, September 2019.

Dr.GomatamMohanaCharyulu, Associate Professors of English, Dept of Science and Humanities, VFSTR Deemed to be University, Vadlamudi, Guntur, AP India.

Dr VijayaBabuPalukuri, Associate Professors of English, Dept of Science and Humanities, VFSTR Deemed to be University, Vadlamudi, Guntur, AP India.

Mr. G NageswaraRao, Asst. Professors \& Research Scholars of English, Dept of Science and Humanities, VFSTR Deemed to be University, Vadlamudi, Guntur, AP India

Mr. U Sriranganath, Asst. Professors \& Research Scholars of English, Dept of Science and Humanities, VFSTR Deemed to be University, Vadlamudi, Guntur, AP India. are evaluated in the practical manners. This paper projects a kind of practical study taken up at the VFSTR Deemed to be

University AP India for the first year students counselled and examined in the class room. It also discusses the practical implication of using Just A Minute as a tool and recognises the findings of the study.

\section{ORIGIN OF THE STUDY}

Public Speaking Skills are highly needed for all the aspirant of training and placements. Intrusion of educational organisations into this skill is a practicable and reasonable one. Various technological tools are designed to facilitate these skills. It also require from the presenter a consistent use of their verbal and nonverbal approaches. The biggest challenge at this juncture is to evaluate the performance of the presenters with accuracy and maintenance of time. However, during the couple of years research on public speaking skills is undertaken with full dynamism and support to enhance the skills of the presenters. It is also observed while presenting their views and verbal opinions, the presenters body posture, use of platform given for presentation, facial expressions, eye contact, hand gestures and others. The study on using JAM designed to support in enhancing public speaking skills tries to explore various elements involved in it. Usage of the tool provides the examiner to evaluate the non verbal aspects like gestures, voice modulation and other. The impact of the JAM tool is studied showing positive results in different conditions.

\section{RATIONALE OF THE STUDY}

In this study, usage of JAM as a tool to enhance public speaking skills is tested in a class room following an exploratory and practical approach. It focused on three objectives;

i. To explore implications of investigation the use of JAM tool in a regular learning process inside the class room

ii. To transit the desired information and provide the expected impact on the learners

iii. To contribute more comprehensive learning scenario for learners

However, the study shows evidence that the performance of the learners is improved as per the evaluation of JAM sessions in the class rooms. Therefore, the second objective of the study has an insight into preparation and practice for presentation relate to the trained presentation. In brief, to what extent does thelearner

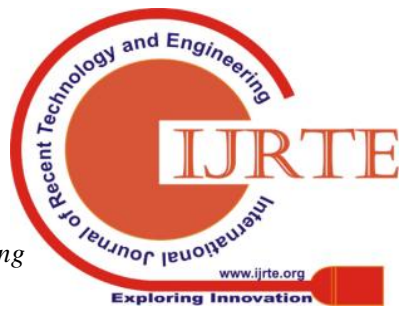


agree with PSS that presentation is improved.

\section{METHODOLOGY}

This study is being conducted in four sections with three cycles at under graduate Technical students who passed EAMCET/JEE/Entrance conducted by concern University. In each section all the 60-70 students are taken up for the study representing individually presenting the topics given by the faculty. The presentation about the topic is in twice at two sessions to examine and understand the variation between the first and second one. All these presentations are recorded and exhibited to the presenters to make a self analysis.

\section{PROCEDURE}

Narrowing down the study, the authors of this paper examined in section 13 of B.Tech First year CSE and IT students comprising of 60 members. All the participants are given Three minutes of time to present their ideas and one minute to conclude the topic. To make this study more effective, the four authors of the this paper in two groups have taken 30 students each to evaluate them at global score by one and individual score by another sitting at different places in the class room. To make their presentation, at the initial state in the first presentation, 30 topics were given at the random lottery system to the students. After presentation each student moved to another room for practice sessions. Before presentation, every participant is given a briefing about their presentation. After a day, again the presentation were organised for the participants at two slots. This facilitates the presenter to make correction in their previous presentation as the feedback for each presenter is given by the authors. It also makes them to improve their baseline of presentation standing alone in front of all the students.

Figure: 1: Public Speaking Skills Presentation in the Class room.

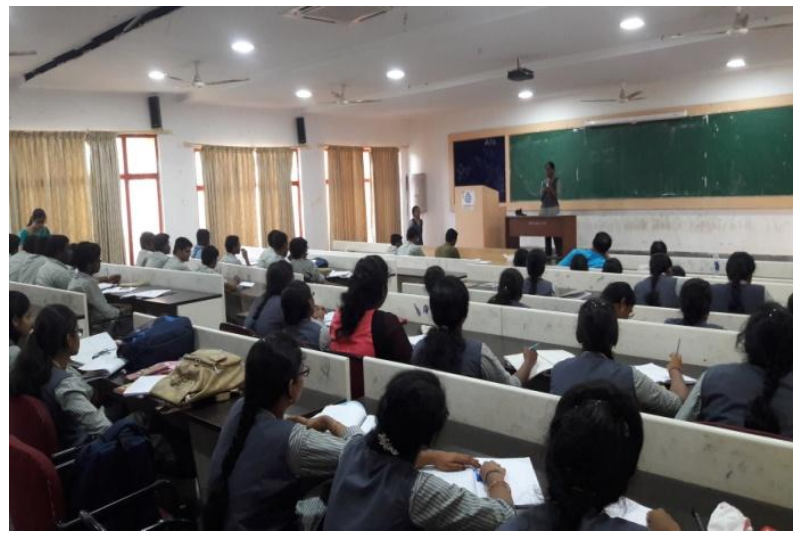

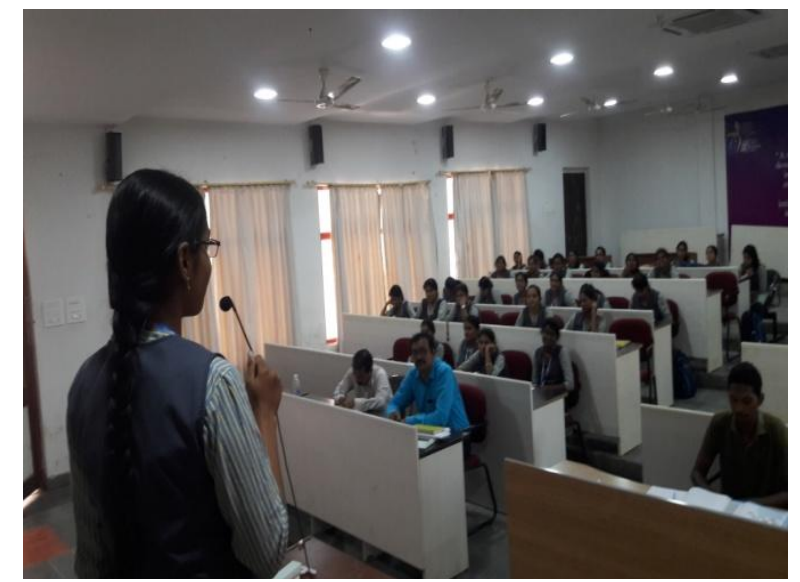

The presentation of the Public speaking in the class rooms has been clearly observed under various components of the verbal and non verbal elements. The influence of public speaking on participants is immense and marched towards the objective of the study.

\section{MATERIALS USED FOR STUDY}

to examine the presentation of the participants, the file containing the list of topics displayed on the notice board of the section. The procedure of eight Likert- scale items are given where the first part of the items refer to general assessment on the topics consists at about 50 ranging from contemporary social and technical issues to general societal regular situations. the later part of the scale is measured through participant presentation, confidence levels, knowledge of the topic, activeness in participation, competitive spirit and so on. In addition to these elements, a few specific nonverbal approaches like posture, gesture, voice, quality and use of pauses and a few others are also measured through observations. At the end of the each presentation, one of the authors took the charge of giving possible suggestions, modification and rectification of identified drawbacks of the presentation in the form of counselling. (See Fig 1). It motivated the overall presentation and made a kind of self analysis by the learner to present better in the future presentations. All these logistics are recorded and filed for the purpose of the data analysis.

\section{FINDINGS}

the evaluation of the presentations made by 62 participants of the Sec 13 reveal major general aspects of the public speaking skills as discussed by Parvis, L.F (2001) and DeCaro, PA (2011) in their "Origin and Importance of the Public Speaking". The evaluation of the presentations in terms of Global Score 5.31 Analytical score 6.70 at the cycle level ONE reveal a difference of 1.39 in an average. The highest score at the GS in cycle ONE 7.5 and AS is 9.0 which come across the differerce of 1.5. the fraction of .11 is the major difference in the highest scoring levels at GS and AS. When it comes to Cycle TWO, there is a difference of 3.01 at the Grand Score levels of the two cycles. After giving a gap, the presntaters rectifications of the feed back and the improvement in their presentation, focusing their attention on the subject verbal and non verbal issues captured the difference in the presentation levels.

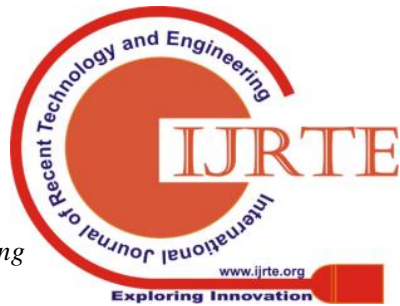


Chart-1

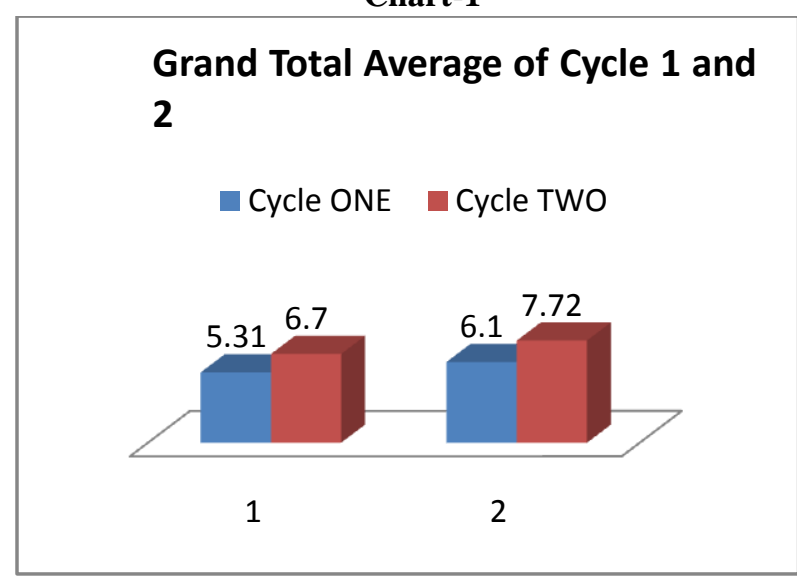

To establish the facts found through the observation of the presentations, JAM tool as discussed by Pearson's $r$ to calculate the correlation between the score levels of the presentations at various levels. The differences as shown in the chart 1 , is differences of 1.5 and 1.30 which show the fraction of 0.11 . The objective of the study is to explore the importance of the JAM as a tool for the public speaking skills display the strongest correlation between cycle ONE and cycle TWO. The comparison of the statistics and analysis of the scores significantly presented show that there is improvement in the presentations from cycle ONE to cycle TWO.

Chart 2:

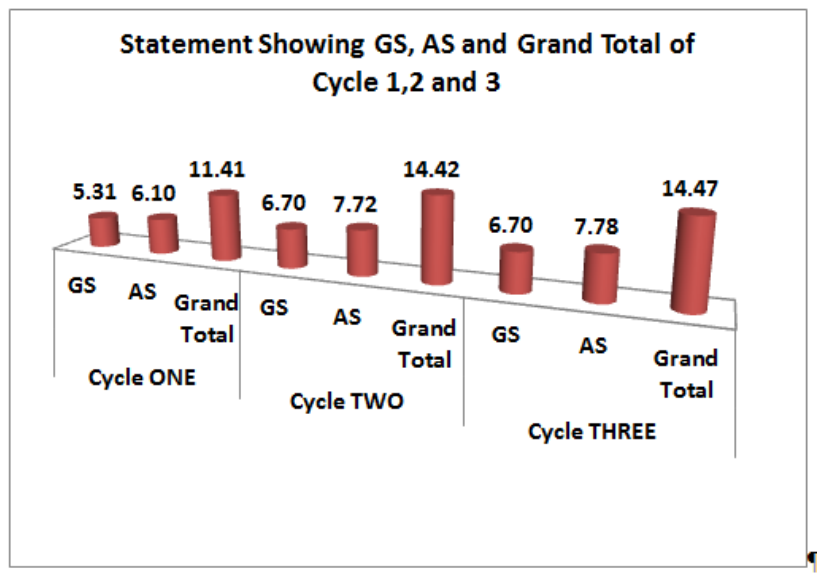

While interacting with the participants, it is clearly revealed that the regular practice of Public Speaking Skills through JAM (Just a Minute) as a tool give a significant improvement in the confidence levels of the presenters. The stage fear, content knowledge, social awareness and technical knowledge and a few other components are played a strong role in the participation. A few of participants suggested to organise such sessions monthly once or Bi-monthly once for the benefit of the presenters.

\section{ARGUMENT}

the present practical study in the use of JAM as a tool for enhancing public speaking skills among the technical graduate students has many implications. It is organised in the class room under real time situations of formal presentations. Prof SharadaAllemneni and team carefully designed the entire concept for the practical study allowing consistent and replicable resources.

"We encountered two major challenges while designing the practical course of the study. They are time and location. As the university has hectic schedule, we suggested the team members to organise them in the class room without making any academic disturbance in the class room at 2.00 to $4.00 \mathrm{pm}$ IST."

Moreover, the practical study had given a chance to make all the members of the section to participate in the study at three cycles. It allowed the authors to assess significant results. It is completely different from the previous practical study using JAM as a tool for developing public speaking skills. This study is individual and to be presented in a quiet room in front of all the other presenters. It shows the second objective of the study to influence and encourage the audience to participate and present themselves. The open presentation gives a kind of inspiration to other participants subject to condition that they should not speak on the topics which the other presenters already brought to the notice of all. To conclude, the result reveal that the assessment through JAM as a tool clearly mentions that there is a possible improvement in the Public Speaking skill showing the difference in correlation between cycle ONE and TWO. The second one is the assessing parameters like Nonverbal, Grammar, Vocabualry, Pronunciation at analytical level and the general observations in Global score exhibit the possible improvement. Introduction of JAM as tool add to the creative ability of extempore and ample situations for the acquisition of the public speaking skills. So this study showed definite improvement of using the tool to support various practices of JAM as a public speaking skill.

\section{SCOPE FOR FURTHER STUDY}

the present study is only limited to JAM as tool, but there is a huge scope for the expansion on available other tools like Poster Description and Group Discussions. As per as the public speaking is concerned, there some practices of teaching and learning Public Speaking skills as suggested by Mitchell, VW and Bakewell C. (1995)

\section{REFERENCES}

1. De Caro, PA: Origin of Public Speaking. In : the Public Speaking project, Chapter 2, 2011.

2. Parvis, LF: The Importance of Communication and Public Speaking Skills , J. Environ Health 2011.

3. Hinton, J.S: The Impact of self directed videotape feedback on Students Self reported levels of Communication Competence and Apprehension. Commun.Edu. 1998.

4. Mitchell.VW: Learning without doing enhancing ora presentation skills through peer review. Manage Learn 1995.

5. Prof. SharadaAllemneni, Head, Division of Humanities, VFSTR, declaration of Design of the course, Divisional meeting, August, 2019 


\section{ACKNOWLEDGEMENT}

This practical study is taken up in Vignan's Foundation for Science Technology Research, Deemed to be University, Vadlamudi,, AP India under the speaking improvement scheme for I Year B. Tech students taken up by Division of

Humanities, Department of Science and Humanities.

\section{ANNEXURE -1}

\begin{tabular}{|c|c|c|c|c|c|c|c|c|c|c|}
\hline \multirow[t]{2}{*}{ SL. } & \multirow[t]{2}{*}{ REGD. } & \multicolumn{3}{|c|}{ Cycle ONE } & \multicolumn{3}{|c|}{ Cycle TWO } & \multicolumn{3}{|c|}{ Cycle THREE } \\
\hline & & GS & AS & Grand Total & GS & AS & Grand Total & GS & AS & Grand Total \\
\hline 1 & 191FA04062 & 5 & 6.5 & 11.5 & 9 & 10 & 19 & 9.00 & 10 & 19 \\
\hline 2 & 191FA04063 & 6 & 7 & 13 & 8 & 8 & 16 & 8.00 & 9 & 17 \\
\hline 3 & 191FA04064 & 6 & 6 & 12 & 7 & 8 & 15 & 7.00 & 9 & 16 \\
\hline 4 & 191FA04066 & 5 & 7 & 12 & 7 & 7 & 14 & 7.00 & 8 & 15 \\
\hline 5 & 191FA04067 & 6 & 8 & 14 & 7 & 7 & 14 & 7.00 & 7.5 & 14.5 \\
\hline 6 & 191FA04068 & 7.5 & 9 & 16.5 & 8 & 10 & 18 & 8.00 & 10 & 18 \\
\hline 7 & 191FA04069 & 6 & 6.5 & 12.5 & 7 & 8 & 15 & 7.00 & 8 & 15 \\
\hline 8 & 191FA04070 & 5 & 5.5 & 10.5 & 7 & 8 & 15 & 7.00 & 8 & 15 \\
\hline 9 & 191FA04071 & 5 & 8 & 13 & 8 & 10 & 18 & 8.00 & 10 & 18 \\
\hline 10 & 191FA04073 & 6 & 8 & 14 & 7 & 8 & 15 & 7.00 & 8 & 15 \\
\hline 11 & 191FA04074 & 5.5 & 6.5 & 12 & 7 & 8 & 15 & 7.00 & 8 & 15 \\
\hline 12 & 191FA04075 & 5 & 5.5 & 10.5 & 6 & 7 & 13 & 6.00 & 7 & 13 \\
\hline 13 & 191FA04076 & 3.5 & 4 & 7.5 & 6 & 7 & 13 & 6.00 & 7 & 13 \\
\hline 14 & 191FA04078 & 5 & 6.5 & 11.5 & 7 & 8 & 15 & 7.00 & 8 & 15 \\
\hline 15 & 191FA04079 & 5 & 5.5 & 10.5 & 8 & 8 & 16 & 8.00 & 8 & 16 \\
\hline 16 & 191FA04081 & 6 & 6.5 & 12.5 & 6 & 10 & 16 & 6.00 & 10 & 16 \\
\hline 17 & 191FA04082 & 6 & 9 & 15 & 7 & 7 & 14 & 7.00 & 7 & 14 \\
\hline 18 & 191FA04084 & 7 & 5 & 12 & 7 & 7 & 14 & 7.00 & 7 & 14 \\
\hline 19 & 191FA04086 & 5 & 6 & 11 & 6 & 7 & 13 & 6.00 & 7 & 13 \\
\hline 20 & 191FA04087 & 6 & 7 & 13 & 6 & 7 & 13 & 6.00 & 7 & 13 \\
\hline 21 & 191FA04088 & 6 & 7.5 & 13.5 & 7 & 10 & 17 & 7.00 & 10 & 17 \\
\hline 22 & 191FA04089 & 5 & 7 & 12 & 6 & 7 & 13 & 6.00 & 7 & 13 \\
\hline 23 & 191FA04090 & 6 & 5.5 & 11.5 & 6 & 7 & 13 & 6.00 & 7 & 13 \\
\hline 24 & 191FA04091 & 6 & 6.5 & 12.5 & 6 & 7 & 13 & 6.00 & 7 & 13 \\
\hline 25 & 191FA04092 & 5 & 7.5 & 12.5 & 7 & 8 & 15 & 7.00 & 8 & 15 \\
\hline 26 & 191FA04094 & 6 & 7 & 13 & 6 & 7 & 13 & 6.00 & 7 & 13 \\
\hline 27 & 191FA04095 & 6 & 5.5 & 11.5 & 6 & 8 & 14 & 6.00 & 8 & 14 \\
\hline 28 & 191FA04096 & 5.5 & 5.5 & 11 & 7 & 7 & 14 & 7.00 & 7 & 14 \\
\hline 29 & 191FA04098 & 4 & 4.5 & 8.5 & 7 & 8 & 15 & 7.00 & 8 & 15 \\
\hline 30 & 191FA04099 & 5 & 5.5 & 10.5 & 7 & 8 & 15 & 7.00 & 8 & 15 \\
\hline 31 & 191FA04100 & 5 & 5 & 10 & 7 & 7 & 14 & 7.00 & 7 & 14 \\
\hline 32 & 191FA04101 & 6 & 7.5 & 13.5 & 7 & 7.5 & 14.5 & 7.00 & 7.5 & 14.5 \\
\hline 33 & 191FA04102 & 6 & 6 & 12 & 6 & 6 & 12 & 6.00 & 6 & 12 \\
\hline 34 & 191FA04103 & 5 & 5 & 10 & 6 & 7 & 13 & 6.00 & 7 & 13 \\
\hline 35 & 191FA04104 & 5 & 6 & 11 & 6 & 7 & 13 & 6.00 & 7 & 13 \\
\hline 36 & 191FA04105 & 5 & 6 & 11 & 6 & 6 & 12 & 6.00 & 6 & 12 \\
\hline 37 & 191FA04106 & 5 & 5 & 10 & 6 & 8 & 14 & 6.00 & 8 & 14 \\
\hline 38 & 191FA04107 & 4.5 & 5 & 9.5 & 7 & 7 & 14 & 7.00 & 7 & 14 \\
\hline 39 & 191FA04108 & 5 & 6 & 11 & 6 & 8 & 14 & 6.00 & 8 & 14 \\
\hline 40 & 191FA04110 & 6 & 7.5 & 13.5 & 7 & 8 & 15 & 7.00 & 8 & 15 \\
\hline 41 & 191FA04111 & 5 & 4.5 & 9.5 & 7 & 7 & 14 & 7.00 & 7 & 14 \\
\hline 42 & 191FA04112 & 6 & 8 & 14 & 7 & 8 & 15 & 7.00 & 8 & 15 \\
\hline 43 & 191FA04113 & 5 & 5 & 10 & 7 & 8 & 15 & 7.00 & 8 & 15 \\
\hline
\end{tabular}


International Journal of Recent Technology and Engineering (IJRTE) ISSN: 2277-3878, Volume-8, Issue-2S11, September 2019

\begin{tabular}{|c|c|c|c|c|c|c|c|c|c|c|}
44 & 191 FA04114 & 7 & 8 & 15 & 7 & 8 & 15 & 7.00 & 8 & 15 \\
\hline 45 & 191 FA04115 & 6 & 7 & 13 & 7 & 7 & 14 & 7.00 & 7 & 14 \\
\hline 46 & 191 FA04116 & 5 & 5.5 & 10.5 & 7 & 10 & 17 & 7.00 & 10 & 17 \\
\hline 47 & 191 FA04118 & 4 & 4.5 & 8.5 & 7 & 10 & 17 & 7.00 & 10 & 17 \\
\hline 48 & 191 FA04119 & 5 & 5 & 10 & 7 & 7 & 14 & 7.00 & 7 & 14 \\
\hline 49 & 191 FA04120 & 7 & 9 & 16 & 6 & 8 & 14 & 6.00 & 8 & 14 \\
\hline 50 & 191 FA04578 & 4 & 4 & 8 & 7 & 8 & 15 & 7.00 & 8 & 15 \\
\hline Average & & $\mathbf{5 . 3 1}$ & $\mathbf{6 . 1 0}$ & $\mathbf{1 1 . 4 1}$ & $\mathbf{6 . 7 0}$ & $\mathbf{7 . 7 2}$ & $\mathbf{1 4 . 4 2}$ & $\mathbf{6 . 7 0}$ & $\mathbf{7 . 7 8}$ & $\mathbf{1 4 . 4 7}$ \\
\hline
\end{tabular}

